\title{
Problems with the Identification of 'Problematic' Cannabis Use: Examining the Issues of Frequency, Quantity, and Drug Use Environment
}

\author{
Mark Asbridge $^{a} \quad$ Cameron Duff $^{d}$ David C. Marsh ${ }^{b}$ Patricia G. Erickson ${ }^{c}$ \\ a Department of Community Health and Epidemiology, Dalhousie University, Halifax, N.S., b Northern Ontario School of \\ Medicine, Sudbury, Ont., and ${ }^{C}$ Centre for Addiction and Mental Health, and Department of Sociology, University of \\ Toronto, Toronto, Ont., Canada; ${ }^{\mathrm{S}}$ Social Sciences and Health Research Unit, School of Psychology and Psychiatry, \\ Monash University, Melbourne, Vic., Australia
}

\section{Key Words}

Canada $\cdot$ Cannabis · Problematic use $\cdot$ Screening

instruments $\cdot$ Critical analysis

\begin{abstract}
Considerable recent attention has focused on how harmful or problematic cannabis use is defined and understood in the literature and put to use in clinical practice. The aim of the current study is to review conceptual and measurement shortcomings in the identification of problematic cannabis use, drawing on the WHO ASSIST instrument for specific examples. Three issues with the current approach are debated and discussed: (1) the identification of problematic cannabis use disproportionately relies on measures of the frequency of cannabis consumption rather than the harms experienced; (2) the quantity consumed on a typical day is not considered when assessing problematic use, and (3) screening tools for problematic use employ a 'one-size-fits-all approach' and fail to reflect on the drug use context (networks and environment). Our commentary tackles each issue, with a review of relevant literature coupled with analyses of two Canadian data sources - a representative sample of the Canadian adult population and a smaller sample of adult, regular, long-term cannabis users from four Canadian cities - to further articulate each point. This article concludes with a
\end{abstract}

\section{KARGER}

E-Mail karger@karger.com

www.karger.com/ear discussion of appropriate treatment interventions and approaches to reduce cannabis-related harms, and offers suggested changes to improve the measurement of problematic cannabis use.

(c) 2014 S. Karger AG, Basel

\section{Introduction}

Recent debates have revealed many limitations in the research literature about the ways cannabis use and its adverse consequences are studied [1-9]. Different perspectives abound on how to screen for potential harmful or problematic cannabis use, to whom these definitions are applied, and whether the available tools offer utility in differentiating 'safe' versus 'risky' cannabis consumption. While cannabis is the most widely used illicit substance globally [10], decades of study have demonstrated that the majority of mainly infrequent users suffer negligible health effects $[11,12]$. Indeed, patterns of moderate, controlled use predominate for the majority of adult consumers, such that daily cannabis users are often hard to distinguish, in terms of health, social, and economic markers, from individuals who have never used the drug [13-15]. Nevertheless, researchers have identified a range of potential harms, particularly in relation to long-term (c) 2014 S. Karger AG, Basel

$1022-6877 / 14 / 0205-0254 \$ 39.50 / 0$ 
heavy use, while the associated risks of exposure in youth dictate caution and the importance of prevention [1622].

These problems, and the growing global prevalence of cannabis consumption, have prompted various efforts to characterize and identify problematic cannabis use $[1,2$, 4]. This article reviews some of these efforts, asking conceptual questions regarding the ways cannabis use is classified as problematic or harmful, as well as practical questions on how problematic use may be measured and identified. Framed as such, our review addresses three key concerns. First, what role does frequency of consumption play in defining problematic use? Second, should the quantity of cannabis consumed on a typical day be considered when assessing problematic use? Finally, what role does social context play in defining, moderating, and/or exacerbating problematic use?

We examine these issues from a broad social epidemiological perspective, summarizing the existing research in the fields of addiction, medicine, and public health, while examining one specific screening tool - the Alcohol, Smoking and Substance Involvement Screening Test (ASSIST) [23] - to help articulate our main points regarding the classification of problematic cannabis use. We will focus on the ASSIST tool because of its prominence in the design of brief intervention and treatment applications for cannabis; however, the concerns raised in our review are not specific to the ASSIST instrument and may apply to all instruments employed to screen or differentiate more from less harmful cannabis use. While we cannot address all concerns with how problematic use is conceptualized and measured (i.e. issues of cannabis dose and potency, and heterogeneity and confusion in DSMIV definitions of cannabis dependence) [24, 25], our broad goal is to draw attention to what we see as fundamental concerns with how problematic use is defined and understood, and to offer direction on how we might avoid misclassifying regular, nonproblematic users, with greater consideration of use patterns and contexts. This work has important policy implications. In jurisdictions with a strong orientation to public health and prevention, a more nuanced approach to distinguishing harmful types of cannabis consumption from all consumption seems warranted. Similarly, in those locales where enormous resources are spent on enforcement of the prohibition of cannabis use, often at the expense of treatment and prevention efforts, the design of alternative, less punitive approaches has been a major focus of policy discussions [26, 27]. Our work, then, will provide additional data to inform these discussions.

Assessing Problematic Cannabis Use

\section{Unpacking 'Problematic' Cannabis Use}

Several tools have been developed to screen for 'harmful' or 'problematic' cannabis use, ranging from simple instruments, such as the 5-item Severity of Dependence Scale (SDS) [28] to more complex, multi-item scales including the Cannabis Use Disorders Identification Test (CUDIT) [29] and the Cannabis Abuse Screening Test (CAST) $[30,31]$. The focus of the current study, i.e. the more widely utilized ASSIST instrument, was developed as a screening tool with international applicability to identify individuals involved in substance use who may be in need of further intervention. Designed for use in primary-care settings through face-to-face interaction with a health professional, the ASSIST helps 'to identify people with both moderate and severe substance use problems, and is capable of detecting risky, hazardous or harmful substance use, where the level of risk can determine the most appropriate treatment for the individual' $[32$, p. 1]. Thus the intention is to provide an informed basis for further referral, more in-depth assessment, and a potential therapeutic response. In other words, the ASSIST was developed for use as an efficient screening tool to enable more sophisticated, detailed assessments of consumption, risks, and harms in clinical settings. The recent application of the ASSIST tool in survey research has created a range of novel problems that were not anticipated in the design of the tool, as we shall describe below.

Briefly, the ASSIST includes six questions focusing on the frequency of use and related issues (table 1). The responses to questions $2-7$ are assigned scores: $0-6$ for items $2,3,6$, and $7 ; 0-7$ for item 4 , and $0-8$ for item 5 . Scores are summed to give a final score out of 39 , directing decisions on how to proceed with a respondent. A sum score of $0-3$ is considered low risk for problematic use, and no intervention is recommended; a score of 4-26 indicates a moderate risk, with a suggestion for a brief intervention, consistent with a DSM-IV-TR diagnosis of cannabis abuse, and a score of 27 or more is considered high risk, consistent with a diagnosis of cannabis dependence, with a suggestion of referral to specialist treatment. An international validation demonstrated that the ASSIST performed well in discriminating between nonproblematic substance use (low risk), abuse (moderate risk), and dependence (high risk) [33].

Despite validation efforts, the application of screening instruments to identify individuals at risk for abuse or dependence is often fraught with inaccuracies and inconsistencies [8, 34-36]. The work of Degenhardt et al. [34] 
Table 1. The ASSIST instrument applied to cannabis

\begin{tabular}{|c|c|c|}
\hline Item & & Score \\
\hline $\begin{array}{l}\text { Question 1: In your life, which of the following substance } \\
\text { have you ever used? }\end{array}$ & $\begin{array}{l}\text { No } \\
\text { Yes }\end{array}$ & $\begin{array}{l}0 \\
3\end{array}$ \\
\hline $\begin{array}{l}\text { Question } 2 \text { : In the past } 3 \text { months, how often have you used } \\
\text { cannabis? }\end{array}$ & $\begin{array}{l}\text { Never } \\
\text { Once or twice } \\
\text { Monthly } \\
\text { Weekly } \\
\text { Daily or almost daily }\end{array}$ & $\begin{array}{l}0 \\
2 \\
3 \\
4 \\
6\end{array}$ \\
\hline $\begin{array}{l}\text { Question 3: During the past } 3 \text { months, how often have you } \\
\text { had a strong desire or urge to use cannabis? }\end{array}$ & $\begin{array}{l}\text { Never } \\
\text { Once or twice } \\
\text { Monthly } \\
\text { Weekly } \\
\text { Daily or almost daily }\end{array}$ & $\begin{array}{l}0 \\
3 \\
4 \\
5 \\
6\end{array}$ \\
\hline $\begin{array}{l}\text { Question } 4 \text { : During the past } 3 \text { months, how often has your } \\
\text { use of cannabis led to health, social, legal, or financial } \\
\text { problems? }\end{array}$ & $\begin{array}{l}\text { Never } \\
\text { Once or twice } \\
\text { Monthly } \\
\text { Weekly } \\
\text { Daily or almost daily }\end{array}$ & $\begin{array}{l}0 \\
4 \\
5 \\
6 \\
7\end{array}$ \\
\hline $\begin{array}{l}\text { Question 5: During the past } 3 \text { months, how often have } \\
\text { you failed to do what was normally expected of you } \\
\text { because of your use of cannabis? }\end{array}$ & $\begin{array}{l}\text { Never } \\
\text { Once or twice } \\
\text { Monthly } \\
\text { Weekly } \\
\text { Daily or almost daily }\end{array}$ & $\begin{array}{l}0 \\
5 \\
6 \\
7 \\
8\end{array}$ \\
\hline $\begin{array}{l}\text { Question 6: Has a friend or relative or anyone else ever } \\
\text { expressed concern about your use of cannabis? }\end{array}$ & $\begin{array}{l}\text { No, never } \\
\text { Yes, in the past } 3 \text { months } \\
\text { Yes, but not in the past } 3 \text { months }\end{array}$ & $\begin{array}{l}0 \\
6 \\
3\end{array}$ \\
\hline $\begin{array}{l}\text { Question 7: Have you ever tried and failed to control, } \\
\text { cut down, or stop your use of cannabis? }\end{array}$ & $\begin{array}{l}\text { No, never } \\
\text { Yes, in the past } 3 \text { months } \\
\text { Yes, but not in the past } 3 \text { months }\end{array}$ & $\begin{array}{l}0 \\
6 \\
3\end{array}$ \\
\hline Total ASSIST score (sum of Questions 2-7) & $\begin{array}{l}\text { Low risk/no intervention } \\
\text { Moderate risk/brief intervention } \\
\text { High risk/intensive intervention }\end{array}$ & $\begin{array}{l}0-3 \\
4-26 \\
27+\end{array}$ \\
\hline
\end{tabular}

examining misclassifications of cannabis dependence among cannabis users found that standardized instruments produce what they termed 'diagnostic orphans' to describe individuals who exhibit signs of cannabis dependence without satisfying the criteria for dependence. The reverse, where individuals have been assigned a dependence label despite a limited consumption of cannabis over the life course, has also been noted [37]. Difficulties in establishing a standard unit of consumption for the purposes of assessing the risk of harm are another issue of note [9].

More recently, the ASSIST has appeared in general population surveys to help identify the prevalence of potentially risky cannabis use $[7,8,38,39]$. While not its intended use [40-42], given that the ASSIST was meant to be administered face to face in the presence of an interviewer, its application in population surveys raises important questions about screening for harmful cannabis use, and the uses to which such data may be put. It is notable that the application of the ASSIST in population surveys has often afforded population-wide estimates of the prevalence of cannabis dependence, misuse, and/or harm [7-9]. In many instances, these estimates have been reported in popular media, leading to heated debates regarding the risks and harms associated with cannabis use. In Canada and the USA, for example, media debates pursuant to the reporting of survey data have emphasized the need to enhance criminal justice approaches to cannabis 
consumption, rather than addressing the needs of cannabis users who may benefit from health-oriented rather than punitive responses $[43,44]$. These reports, and the controversies they have inspired, highlight the importance of developing more sensitive and nuanced mechanisms for distinguishing harmful from nonharmful patterns of cannabis use, such that more informed public health and law enforcement policies may be developed. The first issue that requires attention in our view is the role of frequency of consumption in classifying problematic use.

\section{What Is the Role of Frequency in Defining Problematic} Cannabis Use?

One of the key issues in recent debates regarding the character of problematic cannabis use is the contention that any use should merit screening for an elevated risk of a cannabis-related problem $[36,45,46]$. In its scoring, the ASSIST gives substantial weight to the simple frequency of use relative to other potential markers [7, 8, 45]. Despite a scale ranging from 0 to 39 , the threshold for a therapeutic response is low, with a score of 4 or higher indicative of a moderate risk that necessitates further intervention. But what does a score of 4 or higher on an ASSIST screen mean?

It is notable that participants may be assigned a score of 4 simply by indicating on question 2 of the ASSIST that they have consumed cannabis on a weekly basis over the past 3 months. While questions 4-7 speak to potential 'problems' associated with use, a user need not have experienced any of them to be screened at a moderate risk. Moreover, even less frequent use (>monthly) when coupled with a lower frequency response on another item is sufficient for a moderate risk score. For example, indicating a single episode of use in the past 3 months, along with indicating that a friend or relative has expressed concern about one's use at least once in one's lifetime, is sufficient to accrue a score of moderate risk and thus invite the need for a brief intervention. Similarly, a single episode of use in the past 3 months, coupled with the expression of a 'strong desire' to use cannabis at least once in the past 3 months, is sufficient to meet the minimum threshold for moderate risk. The consequences of this low threshold are two-fold: many individuals who regularly use cannabis suffer no problems or harms (false positives), while other individuals who consume infrequently do experience harms (false negatives) [7, 34, 47].

To illustrate this point, we applied the ASSIST criteria to two samples of cannabis users: a 'general-population' sample and a 'long-term-user' sample. The first sample (the general-population sample) was drawn from the 2009/2010 iteration of the Canadian Alcohol and Drug Use Monitoring Survey (CADUMS) of 13,082 respondents from all 10 provinces, which represent 25,957,435 Canadian residents aged 15 years and older. The overall response rate was $44.7 \%$, and population weights were applied to all analyses of the CADUMS [48]. The second sample (long-term users) drew on the Four Provinces THC and Tobacco Study, a multi-site, mixed-methods study involving interviews with 165 adult, socially integrated, long-term cannabis users residing in four Canadian cities - Halifax, Montreal, Toronto, and Vancouver - and completed in 2008/2009 [49]. Participants were recruited via a modified respondent-driven sampling protocol designed to access hidden populations and thus providing a more representative sample than a self-selected or convenience sample $[36,50,51]$. The eligibility criteria for this study were defined as: (1) having used cannabis as least twice a month or at least 24 times a year for at least 5 years, (2) being either employed (including work inside the home) or a full-time student, (3) having stable housing for at least 6 months in the past year, and (4) being between the ages of 20 and 49 years.

Table 2 provides a descriptive overview of both samples. Some key differences between the samples should be noted. The long-term users were younger, on average, than the general population sample, and a greater proportion were male. Both samples had equal proportions of nonwhite participants, as well as those who reported being single; however, a higher percent of the general-population sample were married, while individuals in the longterm-user sample were more likely to be in a commonlaw/partner relationships. Finally, long-term users reported higher levels of postsecondary education and were more likely to be employed (full, part time, or self-employed) but reported lower levels of household income.

Drawing first on the general-population sample data (table 3$)$, in $2010,8.4 \%(\mathrm{n}=775)$ of respondents, representative of 2.17 million Canadians aged 15 years or older, reported using cannabis at least once in the last 3 months. Applying the ASSIST criteria, 5.3\% $(n=491)$ of the CADUMS sample (equating to $59 \%$ of all past-3months cannabis users), representing 1.37 million Canadians, would screen at moderate or higher risk and thus be eligible for some form of therapeutic intervention. More importantly, given that weekly consumption is a sufficient threshold for screening at moderate risk, 77\% $(\mathrm{n}=196+182)$ of CADUMS respondents who reported consumption patterns indicative of a moderate or high risk would receive that designation solely on the basis of 
Table 2. Descriptive statistics for the long-term-user (4POTTS) and general-population (CADUMS) samples

\begin{tabular}{|c|c|c|c|c|}
\hline \multirow[t]{2}{*}{ Variables } & \multicolumn{2}{|c|}{$\begin{array}{l}\text { Long-term-user sample } \\
(\mathrm{n}=165)\end{array}$} & \multicolumn{2}{|c|}{$\begin{array}{l}\text { General-population sample } \\
(\mathrm{n}=13,071)\end{array}$} \\
\hline & $\mathrm{n}$ & $\%$ & unweighted, n & weighted, $\%$ \\
\hline Age (years) & 165 (total) & 30.5 & & \\
\hline $15-17$ & & (mean) & 279 & 5 \\
\hline $18-24$ & & & 676 & 11 \\
\hline $25-34$ & & & 1,340 & 15 \\
\hline $35-44$ & & & 2,072 & 18 \\
\hline $45-54$ & & & 2,640 & 19 \\
\hline $55-64$ & & & 2,655 & 14 \\
\hline 65 and older & & & 3,372 & 17 \\
\hline $\mathrm{D} / \mathrm{K}$ & & & 48 & 0 \\
\hline \multicolumn{5}{|l|}{ Sex } \\
\hline Male & 92 & 56 & 5,260 & 48 \\
\hline Female & 71 & 43 & 7,822 & 52 \\
\hline Transgender & 2 & 1 & - & - \\
\hline \multicolumn{5}{|l|}{ City/province } \\
\hline Halifax/N.S. & 43 & 26 & 1,008 & 3 \\
\hline Montreal/Que. & 40 & 24 & 1,008 & 24 \\
\hline Toronto/Ont. & 42 & 25 & 1,008 & 38 \\
\hline Vancouver/B.C. & 41 & 25 & 4,009 & 13 \\
\hline Other & - & - & 6,049 & 22 \\
\hline \multicolumn{5}{|l|}{ Canadian born } \\
\hline Yes & 151 & 91 & - & - \\
\hline No & 14 & 9 & - & - \\
\hline \multicolumn{5}{|l|}{ Ethnic or cultural origin } \\
\hline White/European & 145 & 87 & 11,777 & 86 \\
\hline Other & 20 & 13 & 1,305 & 14 \\
\hline \multicolumn{5}{|l|}{ Relationship status } \\
\hline Single & 54 & 33 & 2,366 & 29 \\
\hline Married/engaged & 25 & 15 & 7,064 & 47 \\
\hline Divorced/separated/widowed & 1 & 0.6 & 2,572 & 14 \\
\hline Common law/living with a partner & 48 & 29 & 912 & 9 \\
\hline Steady relationship (>3 months) & 26 & 16 & - & \\
\hline Casual relationship & 11 & 7 & - & \\
\hline \multicolumn{5}{|l|}{ Current accommodation } \\
\hline Owned house/apartment & 40 & 24 & & \\
\hline Rented house/apartment & 120 & 72 & & \\
\hline Other & 15 & 4 & & \\
\hline \multicolumn{5}{|l|}{ Education (most recent) } \\
\hline High school/secondary school or less & 37 & 22 & 5,359 & 38 \\
\hline Trade or technical school & 21 & 13 & 1,162 & 15 \\
\hline Community college/CEGEP & 24 & 14 & 2,053 & 10 \\
\hline University & 67 & 41 & 3,214 & 26 \\
\hline Postgraduate (master's, $\mathrm{PhD}$, etc.) & 16 & 10 & 1,127 & 10 \\
\hline $\mathrm{D} / \mathrm{K}$ & & & 167 & 1 \\
\hline \multicolumn{5}{|c|}{ Employment (main form over the past 12 months) } \\
\hline Self-employed & 30 & 18 & 595 & 4 \\
\hline Full-time & 89 & 54 & 5,302 & 47 \\
\hline Part-time & 22 & 13 & 1,296 & 11 \\
\hline Other & 24 & 15 & 5,889 & 39 \\
\hline
\end{tabular}


Table 2 (continued)

\begin{tabular}{|c|c|c|c|c|}
\hline \multirow[t]{2}{*}{ Variables } & \multicolumn{2}{|c|}{$\begin{array}{l}\text { Long-term-user sample } \\
(\mathrm{n}=165)\end{array}$} & \multicolumn{2}{|c|}{$\begin{array}{l}\text { General-population sample } \\
(\mathrm{n}=13,071)\end{array}$} \\
\hline & $\mathrm{n}$ & $\%$ & unweighted, n & weighted, $\%$ \\
\hline \multicolumn{5}{|c|}{ Household income (USD) } \\
\hline Prefer not to say & 3 & 2 & & \\
\hline Under 14,999 & 25 & 15 & & \\
\hline $15,000-24,999$ & 23 & 14 & & \\
\hline $5,000-34,999$ & 17 & 10 & & \\
\hline $35,000-49,000$ & 33 & 20 & & \\
\hline $50,000-74,999$ & 25 & 15 & & \\
\hline 75,000 and over & 39 & 24 & & \\
\hline Prefer not to say & & & 3,995 & 32 \\
\hline Under 30,000 & & & 1,936 & 12 \\
\hline $30,000-49,000$ & & & 1,811 & 12 \\
\hline $50,000-79,000$ & & & 2,010 & 15 \\
\hline $80,000-99,000$ & & & 898 & 8 \\
\hline 100,000 and over & & & 2,432 & 22 \\
\hline
\end{tabular}
know.

CEGEP = Collège d'enseignement général et professionnel, i.e. general and vocational college; $\mathrm{D} / \mathrm{K}=\mathrm{don}$ 't

their frequency of use (ASSIST item 2), despite failing to report any cannabis-related health, social, legal, or financial problems, issues with family, or a combination thereof (i.e. ASSIST items 3-7).

Turning to the data on long-terms users reported in table 3, based on the ASSIST, almost all (96\%) of the 165 $(\mathrm{n}=106+52)$ participants may be assigned to the moderate-risk category, or higher, on the basis of their frequency of consumption alone. Despite smoking, on average two joints on a typical day and using cannabis on 4 days during the week before the interview, many longterm users did not report experiencing specific cannabisrelated problems, with the most common problem being a strong desire to use.

To further untangle the impact of frequency on screening for risky use, table 4 draws on the general CADUMS population data to present the proportions of past-3months cannabis users $(n=775)$, stratified by frequency of use, to examine the proportion of those who experience cannabis-related problems (based on ASSIST items 3-7). The second-to-last column in table 4 provides the proportion of past-3-months cannabis users $(\mathrm{n}=775)$ who reported having experienced each problem, while the last column provides the same information for users who screened at moderate or high risk $(n=491)$. Three observations can be drawn from table 4. First, feeling a strong desire or urge to use cannabis is the most common issue or problem reported by past-3-months users and by those who screened at moderate or high risk. Second, outside of reporting a desire to use cannabis, the majority of users (either those who had consumed in the past 3 months or those who screened at moderate or high risk) did not report experiencing other cannabis-related problems. For example, approximately $27 \%$ of past-3-months cannabis users and $39.8 \%$ of moderate- or high-risk users reported having driven under the influence of cannabis at least once in the past year. Just over $6 \%$ of past-3-months cannabis users (and $11.7 \%$ of moderate-/high-risk users) indicated health, social, legal, or financial problems in the past 3 months; $8.8 \%$ (13.9\% of moderate-/high-risk users) reported failing to do what was expected in the past 3 months; $8.8 \%$ (15\% of moderate-/ high-risk users) indicated having relatives express concern about cannabis use in the past 3 months, and $4.5 \%$ (9.8\% of moderate-/high-risk users) reported failing to control, cut down, or stop their use in the past 3 months. In addition, as the bottom of table 4 indicates, past-3-months cannabis users experienced, on average, only 0.5 other cannabis-related problems (ASSIST items 3-7), while those screening at moderate or high risk experienced, on average, only 0.9 other problems. Third, the great majority of problematic behaviors (ASSIST items 3-7) were present among the most frequent users - those who consume daily. 
Table 3. Prevalence of cannabis use, ASSIST item scores, and related cannabis use behaviors for general-population survey respondents (2009/2010 CADUMS)

\begin{tabular}{|c|c|c|c|c|}
\hline \multirow[t]{2}{*}{ Cannabis-related problem or harm } & \multicolumn{2}{|c|}{$\begin{array}{l}\text { 2009/2010 CADUMS } \\
\text { (general population) }\end{array}$} & \multicolumn{2}{|c|}{$\begin{array}{l}\text { 4POTTS sample } \\
\text { (long-term users) }\end{array}$} \\
\hline & $\begin{array}{l}\text { unweighted } \\
\text { sample } \\
(\mathrm{n}=13,082), \mathrm{n}\end{array}$ & $\begin{array}{l}\text { weighted } \\
\text { total sample, } \\
\%\end{array}$ & $\begin{array}{l}\text { sample } \\
(\mathrm{n}=165), \mathrm{n}\end{array}$ & sample, \% \\
\hline Cannabis use in the past 3 months & 775 & 8.4 & 165 & 100 \\
\hline Screening at moderate/high risk on the ASSIST & 491 & 5.3 & 165 & 100 \\
\hline Having driven a car under the influence of cannabis & 208 & 2.4 & 24 & 14.5 \\
\hline \multicolumn{5}{|c|}{ ASSIST 2 - How often have you used cannabis in the past 3 months? } \\
\hline Never & 12,254 & 91.6 & 0 & 0 \\
\hline Once or twice & 230 & 2.5 & 0 & 0 \\
\hline Monthly & 167 & 1.6 & 7 & 4.2 \\
\hline Weekly & 196 & 2.0 & 106 & 64.2 \\
\hline Daily & 182 & 2.1 & 52 & 31.6 \\
\hline \multicolumn{5}{|c|}{ ASSIST 3 - Do you have a strong desire or urge to use cannabis? } \\
\hline Never & 12,838 & 97.8 & 21 & 13.3 \\
\hline Once or twice & 39 & 0.4 & 32 & 19.3 \\
\hline Monthly & 36 & 0.3 & 27 & 16.3 \\
\hline Weekly & 57 & 0.8 & 43 & 25.9 \\
\hline Daily & 60 & 0.6 & 42 & 25.3 \\
\hline \multicolumn{5}{|c|}{ ASSIST 4 - Has your cannabis use led to health, social, legal, or financial problems? } \\
\hline Never & 12,994 & 99.4 & 124 & 75.2 \\
\hline Once or twice & 13 & 0.02 & 39 & 23.6 \\
\hline Monthly & 10 & 0.04 & 0 & 0 \\
\hline Weekly & 5 & 0.01 & 2 & 1.2 \\
\hline Daily & 4 & 0.01 & 0 & 0 \\
\hline \multicolumn{5}{|c|}{ ASSIST 5 - Have you failed to do what was normally expected of you because of cannabis use? } \\
\hline Never & 12,972 & 99.3 & 94 & 57.2 \\
\hline Once or twice & 27 & 0.3 & 48 & 28.9 \\
\hline Monthly & 14 & 0.2 & 15 & 9.0 \\
\hline Weekly & 11 & 0.1 & 8 & 4.8 \\
\hline Daily & 2 & 0.004 & 0 & 0 \\
\hline \multicolumn{5}{|c|}{ ASSIST 6 - Has a friend or relative or anyone else ever expressed concern about your use of cannabis? } \\
\hline Never & 12,714 & 96.6 & 71 & 43.4 \\
\hline Yes, but not in the past 3 months & 259 & 2.6 & 44 & 26.5 \\
\hline Yes, in the past 3 months & 58 & 0.8 & 50 & 30.1 \\
\hline \multicolumn{5}{|c|}{ ASSIST 7 - Have you ever tried and failed to control, cut down, or stop your use of cannabis? } \\
\hline Never & 12,815 & 98.0 & 47 & 29 \\
\hline Yes, but not in the past 3 months & 165 & 1.4 & 42 & 25.5 \\
\hline Yes, in the past 3 months & 53 & 0.5 & 76 & 46.1 \\
\hline
\end{tabular}

Taken together, these results underline the disproportionate impact that the inclusion of a simple measure of frequency has on defining problematic and harmful use, leading to the inappropriate labeling, in our view, of many well-functioning regular cannabis users. It is also worth noting that the apparent demand for brief interventions for cannabis consumption suggested in each of these data sets likely far exceeds the capacity to deliver such interventions in Canada. This further suggests the need for a more sensitive means of determining problematic cannabis use.
Given these findings, others have noted that a more appropriate threshold for moderate risk on the ASSIST, i.e. 8 rather than 4 , should be set to improve sensitivity and specificity $[7,8]$. Calibrating the scale in such a way would make it impossible for an individual to screen at moderate or high risk based solely on the frequency of their consumption and would necessitate that an individual demonstrate that they have experienced a more specific cannabis-related problem or multiple problems at a lower frequency to indicate the need for appropriate health care interventions. 
Table 4. Relationship between past-3-months cannabis use frequency and cannabis use problems among the general-population sample (weighted proportions; CADUMS data)

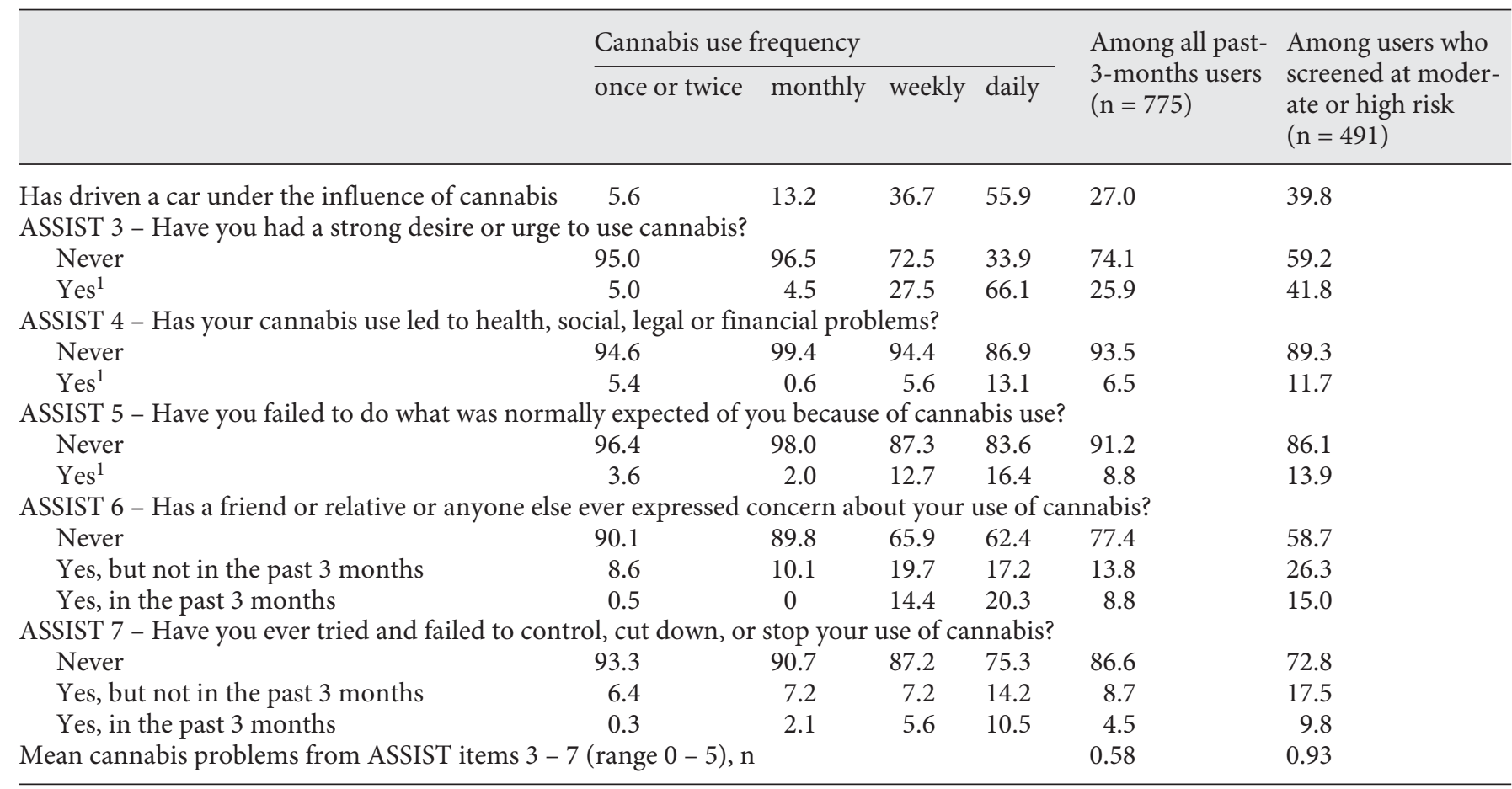

Values are presented as percents unless otherwise stated. ${ }^{1}$ Once or twice, monthly, weekly, and daily use were combined for clarity.

\section{Failure to Consider the Quantity of Cannabis Consumed}

Building on the question of frequency, the second issue we would like to consider points to the failure to measure the quantity of cannabis consumed in screening for risky use [9]. Notably absent from the ASSIST, among other screening tools, are indicators of the amount of cannabis consumed in a typical episode of use $[1,37]$. This absence is surprising given the long-standing attention the issue of quantity consumed has received in the alcohol literature [52-56] and the acceptance in the alcohol field that harmful use should not be based on simple measures of frequency alone [57-59].

Previous research has shown that measures of the quantity of cannabis consumed have effects that are independent of measures of cannabis frequency in predicting cannabis dependence and other related problems [6063]. Quantity indicators employed in previous studies include questions about the number of joints (or equivalents) smoked per day [60-62], the intensity of intoxication during use [63], the amount of time spent 'high' on a given day [60], and the number of ounces consumed per month or week $[62,63]$. The limited development and uptake of indicators of quantity may be a result of challenges scholars have experienced creating a standardized measure and/or unit of consumption, exacerbated by the diverse ways cannabis is consumed (e.g. duration of inhalation), the type of cannabis consumed or the THC potency $[62,64]$, and its illegality [65].

Very recent work by Zeisser et al. [9] examined the role of quantity consumed as a predictor of problematic cannabis use. Drawing on the issue of quantity versus frequency of consumption from the alcohol literature, they began by defining a 'standard joint' (one joint $=0.5 \mathrm{~g}, 5$ bong or pipe hits, or 10 puffs) and then applied this measure to a sample of 665 regular drug users from British Columbia. Zeisser et al. [9] reported that the quantity of cannabis consumed, in standard joints, had an independent and positive effect on the likelihood of cannabis-related problems (ASSIST items 3-7). However, when adjusting for frequency, quantity was only associated with one problem measure - failure to do what was expected; thus, frequency remained a better predictor of cannabis problems than quantity [9]. 


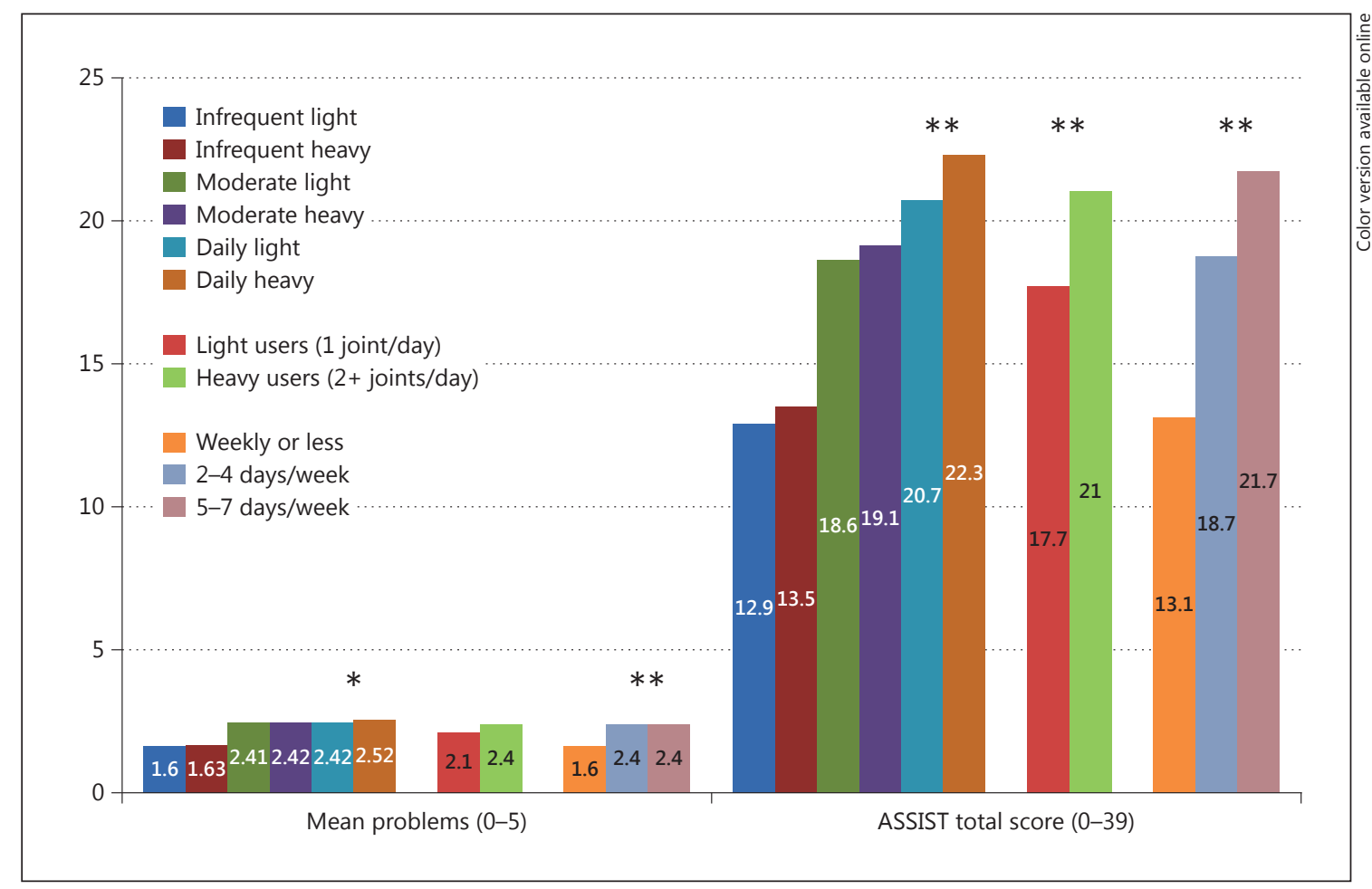

Fig. 1. Mean number of problems (ASSIST items 3-7) and total ASSIST scores by Q/F measure, typical quantity consumed, and frequency of consumption. ${ }^{*} \mathrm{p}<0.05 ;{ }^{* *} \mathrm{p}<0.01$.

Employing the long-term users data introduced above, we further probed the quantity versus frequency issue. However, unlike Zeisser et al. [9], who left quantity and frequency as separate measures, we combined them into a quantity/frequency $(\mathrm{Q} / \mathrm{F})$ measure, drawing on the 'total volume of alcohol consumed in standard drinks per average day' (QFVOLDAY) tool. For alcohol, this measure combines the frequency of consumption (in days) with the volume consumed on a drinking occasion, yielding Q/F thresholds (abstinence, low, hazardous, and harmful). The literature has shown the Q/F measure to provide better predictive utility regarding harmful alcohol consumption relative to simple frequency measures, with clear dose-response effects [53, $54,66-70]$.

Our data on long-term users included the following two questions on typical consumption patterns: (1) 'On a typical day when you use cannabis, roughly how many joints do you usually have?' (count 10 puffs, 5 bong or pipe hits, or $0.5 \mathrm{~g}$ as equivalent to 1 joint), and (2) the total number of days cannabis was used in the past 30 days and in the past 7 days. From this, we created a Q/F typology that measures differing patterns of consumption, in- cluding quantity and frequency, with six distinct categories: (1) infrequent light users (use once per week or less, 1 joint per day); (2) infrequent heavy users (use once per week or less, 2 or more joints per day); (3) moderate light users (use 2-4 days per week, 1 joint per day); (4) moderate heavy users (use 2-4 days per week, 2 or more joints per day); (5) daily light users (use 5-7 days per week, 1 joint per day), and (6) daily heavy users (use 5-7 days per week, 2 or more joints per day).

Employing the above Q/F measure, figure 1 depicts the association of the Q/F of cannabis use with two outcomes: the mean number of cannabis-related problems (ASSIST items 3-7) and the total ASSIST score (0-39). For comparison purposes, we also included a measure of frequency alone and quantity alone, and compared the eta ${ }^{2}$ values (produced from an ANOVA and akin to an $\mathrm{R}^{2}$ value from regression analyses) between measures. We observed a significant, increasing 'dose-response' relationship in moving from infrequent (once a week or less) and light (1 joint per day) use to daily and heavy ( 2 or more joints per day) use for both the mean number of problems $(\mathrm{p}=0.05$; eta $\left.^{2}=0.06\right)$ experienced and the total ASSIST score $(\mathrm{p}=$ 0.00 ; eta $^{2}=0.19$ ). To provide a more direct picture of the 
impact of the quantity consumed, we compared those who used 1 joint per day (light users) with those who used 2 or more joints per day (heavy users) and found that heavy users experienced more problems ( 2.4 vs. $2.1 ; \mathrm{p}=$ 0.20 ; eta $\left.^{2}=0.007\right)$ and reported significantly higher ASSIST scores ( 21.0 vs. $17.7 ; \mathrm{p}=0.007$; eta ${ }^{2}=0.05$ ). Frequency alone also significantly differentiated mean problems $\left(\mathrm{p}=0.01\right.$; eta $\left.{ }^{2}=0.06\right)$ and ASSIST scores $(\mathrm{p}=0.00$; eta $\left.^{2}=0.18\right)$. As such, we argue that a $\mathrm{Q} / \mathrm{F}$ cannabis measure adds to our understanding of problem consumption compared to a measure based solely on frequency or on an ASSIST scale that employs a low threshold for moderate harm (i.e. scores of 4 or higher).

When Thake and Davis [8] compared the utility of the ASSIST, the CUDIT, and a simple measure of daily use in predicting problematic cannabis consumption, they concluded that daily use was adequate (compared to the others) for identifying those using at risky levels. In contrast, our results, along with those of Zeisser et al. [9] and earlier work by Looby and Earleywine [22], suggest that daily light (i.e. 1 joint) users suffer fewer problems than daily heavy users ( $2+$ joints), such that quantity does matter in relation to the assessment of cannabis-related harms. Additionally, these findings align with those from the alcohol literature noting that binge drinking - whether infrequent or daily - has unique and important negative health and social consequences [57].

\section{Does the Drug Use Environment Matter in Defining Problematic Cannabis Use?}

Our final question concerns the failure to consider the role of drug use contexts in attempts to identify problematic or harmful cannabis use. This issue speaks not only to the ASSIST but also to all screening tools aimed at untangling the relationship between consumption and harm. The failure to properly accommodate the effects of context is surprising given the long-standing research confirming the role of context in shaping drug use patterns [71-74]. The fact that existing screening tools for risky cannabis use neglect the role of context raises serious concerns about their ability to accurately identify problematic drug use or to differentiate 'controlled' use from misuse or harmful use [75].

The essential point is that the outcomes of cannabis consumption are not a linear function of individual use patterns. The published literature provides examples where cannabis consumption, while satisfying thresholds for harmful use as defined by the ASSIST, the CUDIT, or the CAST, produces no problematic outcomes, while infrequent consumption that fails to meet thresholds for harm may, in fact, yield a number of negative consequences [34, 37]. As Temple et al. [1] argue, 'factors beyond frequency of use and dependence must play a role in problematic or harmful use'. We must, in other words, resist the temptation to assume that daily consumption is implicitly problematic $[36,76]$. Hammersley [3] notes that 'we do not know whether and how it is possible to consume cannabis heavily and regularly without dependence, because we lack a theory of "dependence" that fits cannabis-using behaviour and can explain why many users do not become dependent, yet some do'.

This line of thought draws on the work of Zinberg [77] on 'drug, set and setting' which emphasizes the manner in which drug effects are moderated by the social setting and its controls. For Zinberg [77], the social setting in which drugs are used shapes the drug use experience, turning a positive experience sour or making a potentially negative experience more pleasant. More recently, Rhodes [78] described what he calls the 'risk environment', which he defines as 'the space - whether social or physical - in which a variety of factors interact to increase the chances of drug-related harm' [78]. Rhodes [78] goes on to identify four environments (physical, social, economic, and policy) which intersect in complex ways to structure risk and harm. This work raises an interesting question regarding how broader environments may shape understandings of problematic cannabis use. Most importantly, can 'enabling' or harm-minimizing environments nullify or mitigate harmful outcomes associated with problematic use? Research indicates that for many cannabis users the protective environment of family, work, peers, and education provides the 'stakes in conformity' that help to balance excessive use [79].

Further insights into the role of context in mediating problematic use can be gleaned from recent debates regarding the putative 'normalization' of illicit drug use including cannabis. At the macro level, there is an abundance of examples of the importance of social and political contexts in driving the cultural normalization of cannabis use in Canada, Australia, the UK, and elsewhere [80]. There is further evidence indicating that local contexts may be equally important in mediating cannabis consumption, illustrated, for example, by lenient local law enforcement practices and collective user strategies that focus on 'controlled use' $[75,80-82]$. The cultural normalization of cannabis exemplified by these developments has had profound effects, we would argue, on how people use and relate to cannabis. Pennay and Moore [83] developed this argument further by describing how the settings and contexts in which drugs are used interact 
with broader processes of cultural normalization to determine whether and in what ways normalization is experienced by individual users. Our own research on longterm cannabis users $[26,80,81]$ has clearly documented that consumption is shaped by a sensitivity to the individual use environment which helps to determine where, when, and with whom use is appropriate and, more importantly, unsuitable.

Collectively, this work points to a need to provide a context-dependent understanding of potentially harmful and/or problematic cannabis use. Such consideration would help to avoid screening errors in which individuals meet a threshold for problematic use despite the absence of cannabis-related problems and despite regarding their own use as nonharmful. Indications of the role of settings in 'controlling' cannabis consumption in ways that either reduce cannabis-related harm or prevent it from emerging in the first place could be taken up in the generation of attitudinal items to sit alongside those that already feature in the ASSIST, the CUDIT, or other screening tools. We would argue that these kinds of concerns could be addressed in the development of items to measure the role of context more directly. Items could, for example, explore the role of peer group norms regarding controlled use, typical and/or 'acceptable' consumption environments, social sanctions regarding 'uncontrolled' or 'excessive' use, and so on. Furthermore, quantity and frequency information should be incorporated into screening for cannabis use problems as well as in diagnostic tools used to identify disorders.

\section{Discussion}

The issues of measurement and conceptualization described above in relation to efforts to screen for problematic or harmful cannabis use highlight the shortcomings of 'one-size-fits-all' approaches to screening. Our examination of the existing literature and of cannabis users from a general population study and from a mixed-methods study of adult, stable, socially integrated users suggests that many cannabis users who may otherwise meet the criteria for being at moderate risk for problematic use are nonetheless able to successfully integrate cannabis use into everyday life with few associated problems. Indeed, our findings advocate that regular use of small amounts of cannabis does not appear to increase an individual's likelihood of experiencing problems, and it does not threaten one's ability to function well and perform expected roles. Even so, the tools used to assess potentially harmful cannabis use invariably serve to classify almost all 'regular' users as problematic users. This is not to say that regular users do not suffer problems; our data and that of many others clearly indicate that a minority of regular users report significant problems at work, in the family, and in day-to-day life. The essential question, then, is how to develop appropriate tools that can disentangle truly harmful use from relatively harmless use and, just as importantly, may identify potentially risky use while avoiding the fallacy of identifying false-positive problematic users based solely on the frequency of their cannabis consumption.

As noted above, the ASSIST, the CUDIT, and other screening tools were designed to be delivered face to face by trained health professionals and not to be included as self-report items in general population surveys. Conversely, the CADUMS data reported above was generated via self-report, which may have affected responses to the ASSIST as face-to-face administration is intended to allow for the interviewer to help a respondent identify harms as well as to identify inconsistencies in reporting $[41,42]$. Nonetheless, the issues we have raised in our review concerning the measurement and conceptualization of problematic cannabis use remain important considerations even when tools like the ASSIST are used as intended. Our exercise was not one of validation (i.e. [7]) but rather points to potential concerns and limitations that are present in the ways we approach the identification of problematic cannabis use and suggests other issues for consideration.

We have not addressed all issues regarding the measurement of problematic use. Missing from our work is a deeper consideration of the question of the dose and potency of cannabis consumed $[84,85]$. This includes indicators of cannabis exposure that capture dose and potency [86] as well as methods of ingestion (smoking, eating, and injecting), or more basic questions of how individuals 'use' (e.g. duration of inhalation) cannabis. The THC potency in cannabis varies considerably over time and both within and across regions (i.e. [87-89]), which may have important implications for individual experiences and the potential for harm. Just as quantity consumed appears to be a superior indicator of problematic cannabis use relative to frequency alone, a more precise indicator of THC potency may alter our thinking about the relationship between frequency of use and harmful use in the same way that we differentiate the consumption of high(i.e. spirits) versus low-volume (beer and cider) alcoholic beverages. 
It is essential, then, that we move to adopt more appropriate thresholds to identify those who may be in need of clinical assessment or intervention in relation to their cannabis use. To this end, we support Davis and colleagues $[7,8]$ in arguing that the minimum threshold for the identification of 'moderate' (and thus problematic) cannabis use on the ASSIST tool should be raised from 4 to 8. Given the large number of cannabis users in the community, it is essential to provide an evidence base that can inform the development of public health campaigns and diagnostic criteria that accurately portray the risks associated with particular patterns of cannabis use. In effectively 'problematizing' upwards of half of all individuals who identify as 'current' cannabis users, measures like the ASSIST may undermine the efficacy of the existing prevention efforts and lead to overestimates of the treatment system capacity required. If unaddressed, such distortions may act to limit the access to treatment for those who may benefit from it, and generate skepticism among users who might not be aware of the risks they could face at higher levels of consumption over time [12].

As has been noted in other public-health contexts, education and harm reduction efforts that fail to speak authentically to the needs of target populations are doomed to fail [90]. While no doubt challenging, the failure to consider issues of quantity consumed - in favor of the far simpler though arguably less meaningful issue of frequency - as well as the overall use pattern and use context has left public health campaigns that address cannabis bereft of an optimally effective evidence base. Like with al- cohol, the frequency of cannabis consumption is a poor proxy for harm experienced. If the problem of quantity consumed could be solved in epidemiological assessments of alcohol use, then the same problem is surely surmountable in relation to cannabis. While few would argue that 1-2 alcoholic drinks per day would justify treatment, much less the threat of arrest, fines, and imprisonment, cannabis users lack guidance for realistic and relatively safe self-regulation of their drug use. The dividend to be gained from the work of devising more precise assessments of risk and harm is the development of a truly effective evidence base to guide meaningful policy initiatives to reduce the harms that may actually be experienced by cannabis users.

\section{Acknowledgements}

We gratefully acknowledge the contribution of other coinvestigators on the research team: Serge Brochu, Marie-Marthe Cousineau, and Andrew Hathaway.

Funding for the Canadian Drug Normalization and Stigma Study was provided by an operating grant from the Social Sciences and Humanities Research Council (SSHRC) of Canada. Mark Asbridge is supported by a Canadian Institutes for Health Research New Investigator Award.

\section{Disclosure Statement}

The study authors have no connection with the tobacco, alcohol, pharmaceutical or gaming industries, and declare no other conflicts of interest.

\section{References}

1 Temple EC, Brown RF, Hine DW: The 'grass ceiling': limitations in the literature hinder our understanding of cannabis use and its consequences. Addiction 2011;106:238-244.

2 Copeland J: The glass ceiling on evidence of cannabis related harms - flawed or just false? Addiction 2011;106:249-250.

3 Hammersley R: Meta-analysis is no substitute for theory. Addiction 2011;106:247-248.

4 Patton GC: Moving beyond the grass ceiling. Addiction 2011;106:246-247.

5 Andreasson S: Is there an epidemiological paradox for illicit drugs? Addiction 2011;106: 248-249.

6 Earleywine M: The elephant in the room with the 'grass ceiling'. Addiction 2011;106:245246.

7 Davis CG, Thomas G, Jesseman R, Mazan R: Drawing the line on risky use of cannabis: assessing problematic use with the ASSIST. Addict Res Theory 2009;17:322-332.
-8 Thake J, Davis CG: Assessing problematic cannabis use. Addict Res Theory 2011;19: 448-458.

-9 Zeisser C, Thompson K, Stockwell T, Duff C, Chow C, Vallance K, et al: A 'standard joint'? The role of quantity in predicting cannabisrelated problems. Addict Res Theory 2012;20: 83-92.

10 United Nations Office on Drugs and Crime: World Drug Report 2009. New York, United Nations, 2009.

11 Room R, Fischer B, Hall W, Lenton S, Reuter P: The Global Cannabis Commission Report: Cannabis Policy - Moving beyond Stalemate. Oxford, The Beckley Foundation, 2008.

$\checkmark 12$ Fischer B, Jeffries V, Hall W, Room R, Goldner E, Rehm J: Lower Risk Cannabis Use Guidelines for Canada (LRCUG): a narrative review of evidence and recommendations. Can J Public Health 2011;102:324-327.
13 Hathaway AD: Cannabis users' informal rules for managing stigma and risk. Deviant Behav 2004;25:559-577.

14 Hathaway AD: Marijuana and lifestyle: exploring tolerable deviance. Deviant Behav 1997;18:213-232.

15 Reilly D, Didcott P, Swift W, Hall W: Longterm cannabis use: characteristics of users in an Australian rural area. Addiction 1998;93: 837-846.

16 Calabria B, Degenhardt L, Hall W, Lynskey M: Does cannabis use increase the risk of death? Systematic review of epidemiological evidence on adverse effects of cannabis use. Drug Alcohol Rev 2010;29:1-13.

17 Hall W, Solowij N: Adverse effects of cannabis. Lancet 1998;352:1611-1616.

18 Fergusson DM, Horwood LJ, Swain-Campbell N: Cannabis use and psychosocial adjustment in adolescence and young adulthood. Addiction 2002;97:1123-1135. 
$\checkmark 19$ Patton GC, Coffey C, Carlin JB, Degenhardt L, Lynskey M, Hall W: Cannabis use and mental health in young people: cohort study. BMJ 2002;325:1195-1198.

20 Hall W, Degenhardt L: Adverse health effects of non-medical cannabis use. Lancet 2009; 374:1383-1391.

21 Asbridge M, Hayden J, Cartwright J: Acute cannabis consumption and motor vehicle collision risk: a systematic review of observational studies. BMJ 2012;344:e536.

22 Looby A, Earleywine M: Negative consequences associated with dependence in daily cannabis users. Subst Abuse Treat Prev Policy 2007;2:1-7.

23 WHO ASSIST Working Group: The Alcohol, Smoking and Substance Involvement Screening Test (ASSIST): development, reliability and feasibility. Addiction 2002;97:11831194.

24 Soellner R: Dependence on cannabis - an ever lasting issue. Subst Use Misuse 2005:40:857867.

25 Agrawal A, Lynskey MT: Does gender contribute to heterogeneity in criteria for cannabis abuse and dependence? Results from the National Epidemiological Survey on Alcohol and Related Conditions. Drug Alcohol Depend 2007;88:300-307.

26 Erickson PG, Hathaway AD: Normalization and harm reduction: research avenues and policy agendas. Int J Drug Policy 2010;21:137139.

27 Room R, Reuter P: How well do international drug conventions protect public health? Lancet 2012;379:84-91.

28 Gossop M, Darke S, Griffiths P, Hando J, Powis B, Hall W, et al: The Severity of Dependence Scale (SDS): psychometric properties of the SDS in English and Australian samples of heroin, cocaine and amphetamine users. Addiction 1995;90:607-614.

29 Adamson SJ, Sellman JD: A prototype screening instrument for cannabis use disorder: the Cannabis Use Disorders Identification Test (CUDIT) in an alcohol dependent clinical sample. Drug Alcohol Rev 2003;22:309-315.

-30 Legleye S, Karila L, Beck F, Reynaud M: Validation of the CAST, a general population Cannabis Abuse Screening Test. J Subst Use 2007; 12:233-242.

- 31 Legleye S, Kraus L, Piontek D, Phan O, Jouanne C: Validation of the Cannabis Abuse Screening Test in a sample of cannabis inpatients. Eur Addict Res 2012;18:193-200.

-32 Humeniuk RE, Ali RA, Babor TF, Farrell M, Formigoni ML, Jittiwutikarn J, et al: Validation of the Alcohol Smoking and Substance Involvement Screening Test (ASSIST). Addiction 2008;103:1039-1047.

33 Humeniuk R, Ali R: Validation of the Alcohol, Smoking and Substance Involvement Screening Test (ASSIST) and pilot brief intervention (electronic resource): a technical report of phase II findings of the WHO ASSIST Project. Geneva, WHO Press, 2006.
4 Degenhardt L, Lynskey M, Coffey C, Patton G: 'Diagnostic orphans' among young adult cannabis users: persons who report dependence symptoms but do not meet diagnostic criteria. Drug Alcohol Depend 2002;67:205212.

35 Earleywine M: Understanding Marijuana Use: a New Look at the Scientific Evidence. New York, Oxford University Press, 2002.

36 Hathaway A, MacDonald S, Erickson PG: Reprioritizing dependence and abuse: a comparison of cannabis clients in treatment with a non-treatment sample of users. Addict Res Theory 2008; 16:495-502.

37 Chen C-Y, Anthony JC: Possible age-associated bias in reporting of clinical features of drug dependence: epidemiological evidence on adolescent-onset marijuana use. Addiction 2003;98:71-82.

38 Cunningham JA, Van Mierlo T: The Check Your Cannabis Screener: a new online personalized feedback tool. Open Med Inform J 2009;3:27.

39 Stea JN, Hodgins DC, Lambert MJ: Relations between delay discounting and low to moderate gambling, cannabis, and alcohol problems among university students. Behav Processes 2011;88:202-205.

40 Humeniuk RE: The Effectiveness of a Brief Intervention for Illicit Drugs Linked to the Alcohol, Smoking and Substance Involvement Screening Test (ASSIST) in Primary Health Care Settings: a Technical Report of Phase III Findings of the WHO ASSIST Randomized Controlled Trial. Geneva, WHO Press, 2008.

41 Humeniuk RE, Henry-Edwards SM, Ali RL, Monteiro M, Poznyak V: The Alcohol, Smoking and Substance Involvement Screening Test (ASSIST): Manual for Use in Primary Care. Geneva, WHO Press, 2010.

42 Humeniuk RE, Henry-Edwards SM, Ali RL, Monteiro M, Poznyak V: Brief Intervention: the ASSIST-Linked Brief Intervention for Hazardous and Harmful Substance Use: Manual for Use in Primary Care. Geneva, WHO Press, 2010.

43 Carter CI, MacPherson D: Getting to Tomorrow: a Report on Canadian Drug Policy. Vancouver, Canadian Drug Policy Coalition, 2013. http://www.drugpolicy.ca/progress/ getting-to-tomorrow (accessed June 10, 2013).

44 Pugh T, Netherland J, Finkelstein R, Frederique K, Meeks SM, Sayegh G: Blueprint for a Public Health and Safety Approach to Drug Policy. New York, New York Academy of Medicine, Drug Policy Alliance, 2013.

45 Thomas G, Flight J, Richard K, Racine S: Toward a Policy-Relevant Typology of Cannabis Use for Canada. Ottawa, CCSA, 2006.

46 Beck F, Legleye S: Measuring cannabis-related problems and dependence at the population level; in Sznitman S, Olsson B, Room R (eds): A Cannabis Reader: Global Issues and Local Experiences: Perspectives on Cannabis Controversies, Treatment and Regulation in Europe. Luxembourg, EMCDDA, 2008, vol 2.
47 Bashford J, Flett R, Copeland J: The Cannabis Use Problems Identification Test (CUPIT): development, reliability, concurrent and predictive validity among adolescents and adults. Addiction 2010;105:615-625.

48 Health Canada: Canadian Alcohol and Drug Use Monitoring Survey (CADUMS). Ottawa, Health Canada, 2010.

49 Hathaway A, Hyshka E, Erickson P, Asbridge M, Brochu S, Cousineau MM, et al: Whither RDS? An investigation of respondent driven sampling as a method of recruiting mainstream marijuana users. Harm Reduct J 2010;7:15.

50 Heckathorn DD: Respondent-driven sampling II: deriving valid population estimates from chain-referral samples of hidden populations. Soc Probl 2002;49:11-34.

51 Hyshka E, Clark S, Lambert L, Plante E, Walker A: Hiding in plain sight: trouble and triumph recruiting mainstream cannabis users in 4 Canadian cities; in G. Szarykcz (ed): In Troubled Waters: Navigating through the Unexpected Challenges and Dilemmas of Social Research. Amherst, Cambria Press, 2010.

52 Bruun K, Edwards G, Lumio M, Mäkelä K, Pan L, Popham RE, et al: Alcohol Control Policies in Public Health Perspective. Helsinki, Finnish Foundation for Alcohol Studies, 1975.

53 English DR, Holman CDJ, Milne E, Winter MJ, Hulse GK, Codde G, et al: The Quantification of Drug-Caused Morbidity and Mortality in Australia. Canberra, Commonwealth Department of Human Services and Health, 1995.

54 Rehm J, Room R, Graham K, Monteiro M, Gmel G, Sempos CT: The relationship of average volume of alcohol consumption and patterns of drinking to burden of disease: an overview. Addiction 2003;98:1209-1228.

55 Maxwell MA: Drinking behavior in the state of Washington. Q J Stud Alcohol 1952;13: 219-239.

56 Straus R, Bacon SD: Drinking in College. New Haven, Yale University Press, 1953.

57 Rehm J: Measuring quantity, frequency, and volume of drinking. Alcohol Clin Exp Res 1998;22:4s-14s.

58 Edwards G, Anderson P, Babor T, Casswell S, Ferrence R, Giesbrecht N, et al (eds): Alcohol Policy and the Public Good. New York, Oxford University Press, 1994.

59 Rehm J, Ashley MJ, Room R, Single E, Bondy $S$, Ferrence R, et al: On the emerging paradigm of drinking patterns and their social and health consequences. Addiction 1996;91: 1615-1621.

60 Chen K, Kandel D, Davies M: Relationships between frequency and quantity of marijuana use and last year proxy dependence among adolescents and adults in the United States. Drug Alcohol Depend 1997;46:53-67.

61 Grant BF, Pickering R: The relationship between cannabis use and DSM-IV cannabis abuse and dependence: results from the $\mathrm{Na}$ tional Longitudinal Alcohol Epidemiologic Survey. J Subst Abuse 1998;10:255-264. 
-62 Stephens RS, Babor TF, Kadden R, Miller M: The Marijuana Treatment Project: rationale, design and participant characteristics. Addiction 2002;97(suppl 1):109-124.

63 Walden N, Earleywine M: How high: quantity as a predictor of cannabis-related problems. Harm Reduct J 2008;5:20-27.

64 Kalant H: Smoked marijuana as medicine: not much future. Clin Pharmacol Ther 2008;83: 517-519.

65 Degenhardt L, Hall W: Extent of illicit drug use and dependence, and their contribution to the global burden of disease. Lancet 2012; 379:55-70.

66 Rehm J, Ashley MJ, Dubois G: Alcohol and health: individual and population perspectives. Addiction 1997;92:S109-S115.

67 Rehm J, Gmel G: Aggregating dimensions of alcohol consumption to predict medical and social consequences. J Subst Abuse 2000;12: 155-168.

68 Dawson D: Methodological issues in measuring alcohol use. Alcohol Res Health 2003;27: 79-86.

69 Dawson DA: Measuring alcohol consumption: limitations and prospects for improvement. Addiction 1998;93:965-968.

70 Stockwell T, Daly A, Phillips M, Masters L, Midford R, Gahegan M, et al: Total versus hazardous per capita consumption as predictors of acute and chronic alcohol-related harm. Contemp Drug Probl 1996;23:441464.

71 Duff C: Towards a theory of drug use contexts: space, embodiment and practice. Addict Res Theory 2007;15:503-519.
72 Moore D: Opening up the cul-de-sac of youth drug studies: a contribution to the construction of some alternative truths. Contemp Drug Probl 2002;29:13-64.

73 Moore D, Dietze P: Enabling environments and the reduction of drug-related harm: reframing Australian policy and practice. Drug Alcohol Rev 2005;24:275-284.

74 Duff C: The importance of culture and context: rethinking risk and risk management in young drug using populations. Health Risk Soc 2003;5:284-299.

75 DeCorte T: Blinding ourselves with science: the chronic infections of our thinking on psychoactive substances; in Hunt G, Milhet M, Bergeron H (eds): Drugs and Culture: Knowledge, Consumption and Policy. Burlington, Ashgate, 2011.

76 Parker H: Normalization as barometer: recreational drug use and the consumption of leisure by young Britons. Addict Res Theory 2005; 13:205-215.

77 Zinberg N: Drug, Set, and Setting: the Basis for Controlled Intoxicant Use. New York, Vail-Ballou Press, 1984.

78 Rhodes T: The 'risk environment': a framework for understanding and reducing drugrelated harm. Int J Drug Policy 2002;13:8594.

79 Waldorf D, Reinarman C, Murphy S: Cocaine changes: the experience of using and quitting. Philadelphia, Temple University Press, 1991.

$\$ 80$ Duff C, Asbridge M, Brochu S, Cousineau M-M, Hathaway AD, Marsh D, et al: A Canadian perspective on cannabis normalization among adults. Addict Res Theory 2001, DOI: 10.3109/16066359.2011.618957.

-81 Brochu S, Duff C, Asbridge M, Erickson P: 'There's what's on paper and then there's what happens, out on the sidewalk': cannabis users' knowledge and opinions of Canadian drug laws. J Drug Issues 2011;41:96-116.
82 Ream G, Johnson BD, Dunlap E, Benoit E: The role of marijuana use etiquette in avoiding targeted police enforcement. Drugs (Abingdon Engl) 2010;17:689-706.

83 Pennay A, Moore D: Exploring the micropolitics of normalization: narratives of pleasure, self-control and desire in a sample of young Australian 'party drug' users. Addict Res Theory 2010;18:557-571.

84 Smith N: High potency cannabis: the forgotten variable. Addiction 2005;100:1558-1560.

-85 King LA, Carpentier C, Griffiths P: Cannabis potency in Europe. Addiction 2005;100:884886.

86 van der Pol P, Liebregts N, de Graaf R, Korf DJ, van den Brink W, van Laar M: Validation of self-reported cannabis dose and potency: an ecological study. Addiction 2013;108: 1801-1808.

87 Potter DJ, Clark P, Brown MB: Potency of $\Delta 9$ THC and other cannabinoids in cannabis in England in 2005: implications for psychoactivity and pharmacology. J Forensic Sci 2008; 53:90-94.

88 McLaren J, Swift W, Dillon P, Allsop S: Cannabis potency and contamination: a review of the literature. Addiction 2008;103:11001109.

89 Burgdorf JR, Kilmer B, Pacula RL: Heterogeneity in the composition of marijuana seized in California. Drug Alcohol Depend 2011; 117:59-61.

90 Baum F: The New Public Health. Oxford, Oxford University Press, 2003. 